\title{
INSTITUTIONS OF HIGHER EDUCATION IN COVID-19 RISK COMMUNICATIONS: TEXAS STUDY
}

\author{
ANDREA BAUER \& MAGDALENA ANNA DENHAM \\ Department of Security Studies, Sam Houston State University, USA
}

\begin{abstract}
This case study research aimed to explore risk communication processes and strategies adopted by Institutions of Higher Education (IHEs) in the state of Texas during COVID-19. Because higher learning and interactions with students during the initial stages of the pandemic resided predominantly in virtual space, the study design considered website content analysis as appropriate in addressing risk communications chosen by universities. Markedly, website content analysis was conducted among 43 IHEs accredited by the Southern Association of Colleges and Schools Commission on Colleges and part of a Texas University System. This sampling replicates previous IHE research in the state. The conceptual model entitled "Conceptual Model for Evaluating Emergency Risk Communication (EERC)" developed in public health was used to ground focused risk communication dimensions to (a) review whether or to what degree messaging from IHEs aligned with the components used by experts; (b) record the types of patterns that are found in messaging as well as characteristics that foster a Disaster Resilient University (DRU); and (c) provide insights on areas that may need more focus to ensure greater efficacy in the future. The ERC model yielded the following dimensions used for analysis: (a) accurate/reliable; (b) open/transparent; (c) clear; (d) tailored messages; (e) consistent/ timely; (f) sufficient; and (g) actionable. In addition to ERC, content regarding technological solutions was assessed from websites of chosen universities to gauge how universities have responded to tools needed during the pandemic to make informed judgments for the campus and to share information openly for the community. Our findings point to various components that IHEs in Texas targeted when communicating COVID-19 related information. For example, less than $60 \%$ of IHE in our sample defined terms, reviewed general COVID-19 information, and identified at risk groups on their respective campuses and only $6 \%$ provided an option for translating information. Meanwhile, IHEs fared generally better at providing timely updates regarding campus operations (i.e., $80 \%$ ). Implications for our finding are discussed within the lens of Disaster Resilient University (DRU).

Keywords: institutions of higher education, Disaster Resilient University, risk communications, college students and COVID-19, public health, digital health technology, evaluating emergency risk communication.
\end{abstract}

\section{INTRODUCTION}

Risk communication defined as the "exchange of real time information, advice and opinions between experts and people facing threats to their health, economic, or social well-being" [1, para. 1] supports prevention and mitigation pre-disaster, preparedness among the population, sharing of information during a disaster, and recovery [2]. Researchers reviewing historical cases of pandemics and crisis communication [3] point out the intricacies of mitigating, preparing, and responding to a public health emergency. These complexities result from maintaining security, supporting the advancement of the economy, and the continuation of routine activities while managing a public health crisis $[3, \mathrm{p}$. 6]. The communication adopted during the Spanish Flu of 1918 stands as a lesson for risk communicators. At the start of the 1918 pandemic, the US government disseminated information on the pandemic in war-news style concealing the truth from the public. Stability and "prosperity" were prioritized over transparency, as fear was perceived as a higher threat. Ultimately, the lack of risk communication from the U.S government and medical field hid the gravity of the virus from the publics placing them at higher risk. Trust in leadership was 
lost due to the concealment of people ill with the virus and the underreporting of deaths. Conversely, in cities, where detailed information was disseminated and mass masking recommended, action replaced fear. Albeit the sole responsibility of the Environmental Protection Agency (EPA) in the 1970s, risk communication in the United States evolved to comprise open communication with the public in the 1980s [4] and to foster urgency in the public where needed and decrease panic where risk was low. Earlier period [5] lacked empathy and understanding for public risk perception, causing outward resentment for public response. Risk communication adopted today emerged from the need to form an alliance between government and corporate entities with the public [4] to communicate - based on the hazard - a level of gravity or confidence needed, and fostering appropriate responses based on the information collected. From this, the field grew as the media, public interests, inclusion of the public, and importance of communicating risks to influence the public became important factors of risk communication and persuasive messaging [5]. This phase took into consideration traits of the audience as well as public perception and in the 1990s risk communications transitioned from a purely persuasive communication focus to focus on "social context" [5, p. 90]. After 9/11 and subsequent anthrax attacks, the need for risk communication was heightened [6]; practices recommended included (a) involving stakeholders; (b) listening to the audience; (c) being transparent and open; (d) utilizing credible sources; (e) providing information to the media; (f) communicating clearly; (g) communicating with compassion; and (h) planning ahead of an incident [6]. Risk communications for public health crises have been especially important because they might address "high rates of infection, significant morbidity, lack of therapeutic measures, and rapid increase in cases" [7, para. 1]. Strategies for risk communication in public health emergencies need to account for individual circumstances, uncertainty, and the lack of trust based on a divided political and public health environment [8]. The strategies to better communicate COVID-19 messaging included communicating with honesty, alleviating fear by sharing "that uncertainty is intrinsic to the practice of environmental and public health science" [8, para. 10], consistency, and coordinating with experts. The World Health Organization (WHO) adds trust, transparency, early communication, listening, and planning to the rules of effective risk communication [9]. Glik provides similar strategies that are viewed as necessary in communicating risks such as trust, credibility, transparency, and accountability [10, para. 6] while others [11] present practices with a focus on risk perception and its impact on public response while acknowledging the complexity of communicating risk. They suggest recommendations to enhance operations which require knowing the audience, understanding that delivery impacts efficacy, and adapting during emergencies. The study [11] determined that (a) trust in leadership leads to risk acceptance; (b) tailoring messages to address public emotions can positively impact risk perception; and (c) transparency and sufficient communication can impact public response. Researchers in Baltimore [12, para. 1] found that communicating with transparency, "timeliness, completeness, and clarity of information..." were important drivers of maintaining trust with the community. Early COVID-19 research on risk communication in Wuhan China [13] provides evidence on the impact of timely information on managing risks and containing the crisis. Indeed, lack of timely information on COVID-19 to the public in Wuhan, China, due to political and stability concerns, had deleterious consequences. Risk communications are inherently linked to risk perception defined as "people's subjective judgments about the likelihood of negative occurrences such as injury, illness, disease, and death" [14, para. 1]. Risk perception affects the effectiveness of risk communications [7] through factors such as trust, origin, control, nature, scope, awareness, imagination, dread, age affected, uncertainty, familiarity, specificity, personal impact, and fun factor [15]. These factors play a role in an individual's 
perception of a risk, potentially impacting the health of the recipient and the community. Ultimately, trust in risk communicators as well as in the risk evaluation processes were found to decrease fear and increase accurate risk perception. During the COVID-19 pandemic, communities have relied on information from various outlets and experts. Reportedly, "infodemic" - an over-abundance of information, of which some is accurate, and some is not, has increased during the pandemic and made absorbing reliable information a challenge subsequently posing risk to public health [16, para. 7]. The danger of an over-abundance of information and unreliable communicators leads to the dissemination of false information which in turn has the potential to cause harm or death at worst and increase anxiety among the population at best [17].

Finally, of importance are risk communication tools that can be leveraged to disseminate risk communication. Digital health technologies empower communities to manage "health and wellness" [18]. Risk communication aims to maximize "public risk awareness", providing up to date data that impacts the community, strengthens transparency, and supports informed decision making [19, para. 1]. The COVID-19 pandemic has displayed the various applications of digital health in support to public health emergencies. For example, WHO recommended the use of monitoring tools in public health emergencies to increase situational awareness about the ongoing crisis [20]. In tandem, researchers [21] agree that technologies "play an integral, increasing, and evolving role in supporting public health responses..." (para. 1). For instance, CDC recommended that reopening universities possess systems/processes set up for students, faculty, and staff to report different COVID-19 details such as positive results, exposure to COVID-19, and symptoms [22]. Digital technology in public health emergencies can play a significant role and in COVID-19 in has been used across surveillance, screening, telemedicine, and mobile applications for various services [23]. Clearly, the scale of the pandemic has emphasized digital health technology as tremendous asset in managing public health emergencies. This research aims to explore risk communication processes and strategies adopted by Institutions of Higher Education (IHEs) during COVID-19 crisis and evaluate their effectiveness in helping to form accurate risk perceptions by the campus community; moreover, the extent and nature of adoption of various platforms and techniques for risk communication dissemination with the campus will be appraised as well. This study supports the mission of emergency management to lessen the vulnerabilities of communities through its ability to respond to natural or manmade disasters [24].

\section{INSTITUTIONS OF HIGHER EDUCATION}

As the coronavirus emerged and spread globally, communities and institutions have been challenged with an atypical disaster. Unlike cyclical or recurring hazards, the COVID-19 pandemic has defied traditional emergency management phases and required ongoing implementation and sharing of recommendations through risk communication due to its continuing spread. Institutions of higher education (IHEs), recognized as critical infrastructure under Homeland Security Presidential Directive 7 (HSPD-7), have had an obligation for ensuring safety through practice of risk communication on their campuses [25]. Uncovering the components of effective messaging found across universities as well as identifying potential gaps supports the concept of a Disaster Resilient University (DRU), which is "an institution capable of adapting to the aftermath of a disaster" [26]. A DRU, encouraged under Presidential Directive-5, requires universities to prepare for and develop systems that follow the National Incident Management System (NIMS). As preparing for all kinds of disasters is challenging and may lead to institutions preparing for the more likely disaster, there is a gap of preparation and planning for atypical disasters [27]. During COVID- 
19, many IHES have had to face the challenges of the virus while maintaining the continuity of operations both in person and online. A coronavirus tracking survey [28] disseminated to universities and colleges in Fall 2020 revealed more than 1,000 universities reporting more than 300,000 coronavirus cases on their campuses and 50 deaths. In Texas specifically, more than 80 schools have reported more than 31,000 cases [28]. According to the Centers for Disease Control and Prevention (CDC), more than $15 \%$ of coronavirus cases have been from individuals aged 18-29, which includes the age group of the majority of college and university students [29]. The prevalence of coronavirus cases on campuses and the potential threat of infection among college students and staff, needed to be managed through "detection and containment of clusters of infection and the interruption of community transmission to mitigate the impact on human health" [30, para. 3]. Measures in managing outbreaks such as surveillance, case identification, preventing community spread, and communication with the public have thus been vital to IHEs in controlling COVID-19. Moreover, because the ages of individuals working, teaching, and learning on campuses range from "younger to older adults", disseminating an accurate level of risk to the community supports the application of appropriate protocols and a safe environment [22]. As the "normal" college experience has included in person classes, housing on and off campus, large gathering school events, and social events, managing COVID-19 on campuses has required communication with the community. The techniques used to reach students on campus can influence the safety and sanitary practices used and the overall safety of the campus. Universities adapting to virtual learning at the beginning of the crisis are now offering a mix of online and in person classes, a hybrid method, with students returning to class and adapting to the new college environment.

As many students have become accustomed to life on campus before the pandemic, risk communication permits information to be grasped and practices to be adopted in order to meet the safety requirements of life on and off campus during COVID-19; online information-sharing necessitates reliable COVID-19 information as well as information on campus operations. The priority of "preserving the health of students, faculty, and staff", has required universities to take on the role as emergency managers [29]. In addition, resilience from institutions of higher education is reflected through the generation of "new capabilities" as well as the "shift to new points of stability" [31, p. 7]. Evaluating the risk communications adopted by universities can help strengthen communications in the midst of the pandemic as well as prepare institutions for future disasters that may require long term risk communication. A "DRU has to be created to ensure an overall culture of preparedness is developed and a campus is properly prepared for all dangers that are unique to it" [27, p. 5]. Indeed, research form the start of the pandemic [32] revealed that students' safety adoptions were necessary, as were students' inclusion in messaging and planning, and leveraging of various communication channels. Recognizing obstacles to risk communication is also essential, in order to raise awareness on the factors that may influence the audience's acceptance and acknowledgment of the information.

Emerging literature on risk communication and college campuses has addressed various subjects from students understanding of the public health emergency to the platforms that students more often use to receive information. Data collected from a study of 483 college student activities and knowledge during the H1N1 influenza [33] administered at a university in the southwestern US determined that more than half of students were actively taking health and safety precautions; however, more than half of students were not knowledgeable of the symptoms of H1N1. The majority could not differentiate H1N1 flu signs and symptoms from the seasonal flu. The findings also determined that less than half of students would take proper isolation measures in case of symptoms or illness. Survey research on risk 
communications on college campuses during COVID-19, targeting 1,000 university students in a Midwestern city and their knowledge of the virus [34] found that majority indicated using "the internet and social media" for news on the coronavirus, less than a quarter (i.e., 18\%) accurately identified the symptoms of the coronavirus, more than $50 \%$ incorrectly identified at risk groups, yet more than $50 \%$ identified the appropriate hand washing time to prevent the spread of the coronavirus. This pattern infers a potential vulnerability of safety, which could be addressed by communicating risks to college students and information relating to public health. With respect to research on risk perception, researchers in China [35] assessed the concept of origin or the decrease in risk perception college students had of their own health versus others. Alarmingly, less than 7\% "of college students thought they were more likely to be infected by COVID-19" and more than $80 \%$ of college students worried about a family member becoming infected by COVID-19 [35, para. 13). Origin amongst college students during COVID-19 pointed to an increase in risk perception of the community exposure to COVID-19, but a decrease in risk perception of students' own risk of virus exposure. Effective and targeted risk communications by IHEs are thus critical considering more than $60 \%$ of information sought by college students in a 5,000-sample survey [36] originated from higher education sources. Others [37] suggested such sources be diversified to connect effectively with young adults (e.g., text message, internet, print media). Because most of research on public health risk communications at IHEs consisted of surveying student, our study aims to contribute to the literature by examining ways in which IHEs themselves disseminated risk communication to student community during COVID-19. As campuses adapt to the "new normal" during the ongoing pandemic, collecting data and disseminating information from and to the public will continue to increase awareness and uphold transparency. As research and updates on COVID-19 and latest developments emerge, risk communication will remain vital in ensuring that individuals have accurate information and practices that are recommended to mitigate risks. Due to restrictions being softened and institutions opening again for operations, fortifying safety and security means delivering information in a manner that permits populations to not only change behaviour but also to continuously practice safety guidelines as the pandemic remains active and extends into latter part of 2021.

\section{METHODOLOGY}

This case study research adopts multimodal content analysis (MMCA) that includes written language, illustrations, links, videos, and applications [38], [39] to explore risk communication processes and strategies adopted by selected IHEs in the state of Texas during COVID-19. Because higher learning and interactions with students during the initial stages of the pandemic resided predominantly in virtual space, websites of selected universities were considered valuable repository to assess risk communication approaches in sharing COVID19 information to the users, determining its efficacy, and identifying areas that could be enhanced in continuing operations. Our sample follows filtering criteria applied in a previous research study [26] and comprises 43 IHEs in Texas that are (a) accredited by the Southern Association of Colleges and Schools (SACS) Commission on Colleges and are part of a Texas University System. Table 1 lists IHEs whose website content was explored in this research. While there is no universal tool to measure the effectiveness of risk communication, the Conceptual Model for Evaluating Emergency Risk Communication (EERC) was used to review to what degree messaging from IHEs align with the components used by experts [40]. Fig. 1 represents components of the EERC as well as criteria for each used in website MMCA. The EERC identifies the following components (a) accurate/reliable; (b) open/ transparent; (c) clear; (d) tailored messages; (e) consistent/timely; (f) sufficiency; and 
Table 1: Texas IHEs represented in the study.

\begin{tabular}{|c|c|}
\hline University of Houston System & University of North Texas System \\
\hline University of Houston & University of North Texas \\
\hline University of Houston - Clear Lake & $\begin{array}{l}\text { University of North Texas Health Science } \\
\text { Center }\end{array}$ \\
\hline University of Houston - Downtown & University of North Texas at Dallas \\
\hline \multicolumn{2}{|l|}{ University of Houston - Victoria } \\
\hline University of Texas System & Texas A\&M University System \\
\hline University of Texas at Arlington & Texas A\&M University \\
\hline $\begin{array}{l}\text { The University of Texas Southwestern } \\
\text { Medical Center }\end{array}$ & Prairie View A\&M University \\
\hline The University of Texas at Austin & Texas A\&M University - Commerce \\
\hline $\begin{array}{l}\text { The University of Texas Medical Branch } \\
\text { at Galveston }\end{array}$ & Tarleton State University \\
\hline The University of Texas at Dallas & West Texas A\&M University \\
\hline $\begin{array}{l}\text { The University of Texas Health Science } \\
\text { Center at Houston }\end{array}$ & Texas A\&M University Kingsville \\
\hline The University of Texas at El Paso & Texas A\&M University - Corpus Christi \\
\hline $\begin{array}{l}\text { The University of Texas Health Science } \\
\text { Center at San Antonio }\end{array}$ & Texas A\&M International University \\
\hline The University of Texas Permian Basin & Texas A\&M University - Texarkana \\
\hline $\begin{array}{l}\text { The University of Texas MD Anderson } \\
\text { Cancer Center }\end{array}$ & Texas A\&M University - Central Texas \\
\hline $\begin{array}{l}\text { The University of Texas Rio Grande } \\
\text { Valley }\end{array}$ & Texas A\&M University - San Antonio \\
\hline \multicolumn{2}{|l|}{$\begin{array}{l}\text { The University of Texas Health Science } \\
\text { Center at Tyler }\end{array}$} \\
\hline \multicolumn{2}{|l|}{ The University of Texas at San Antonio } \\
\hline \multicolumn{2}{|l|}{ The University of Texas at Tyler } \\
\hline Texas State University System & Texas Tech University System \\
\hline Lamar University & Angelo State University \\
\hline Sam Houston State University & $\begin{array}{l}\text { Texas Tech University Health Sciences } \\
\text { Center }\end{array}$ \\
\hline Sul Ross University & Texas Tech University \\
\hline Texas State University & $\begin{array}{l}\text { Texas Tech University Health Sciences } \\
\text { Center at El Paso }\end{array}$ \\
\hline \multicolumn{2}{|l|}{ Lamar State of Institute of Technology } \\
\hline \multicolumn{2}{|l|}{ Lamar State College Orange } \\
\hline Lamar State College Port Arthur & \\
\hline
\end{tabular}

(g) actionable [40]. Fig. 2 expands the EERC to include dissemination through multiple channels using technology. The Accurate and Credible criterion defined as information being up to date and scientifically accurate and noted as a vital component to effective risk communication, uncovers the activities that would support this characteristic when reviewing the websites of institutions of IHEs (e.g., coordination of information from credible resources). The Transparent and Open criterion designates candid information provided to 


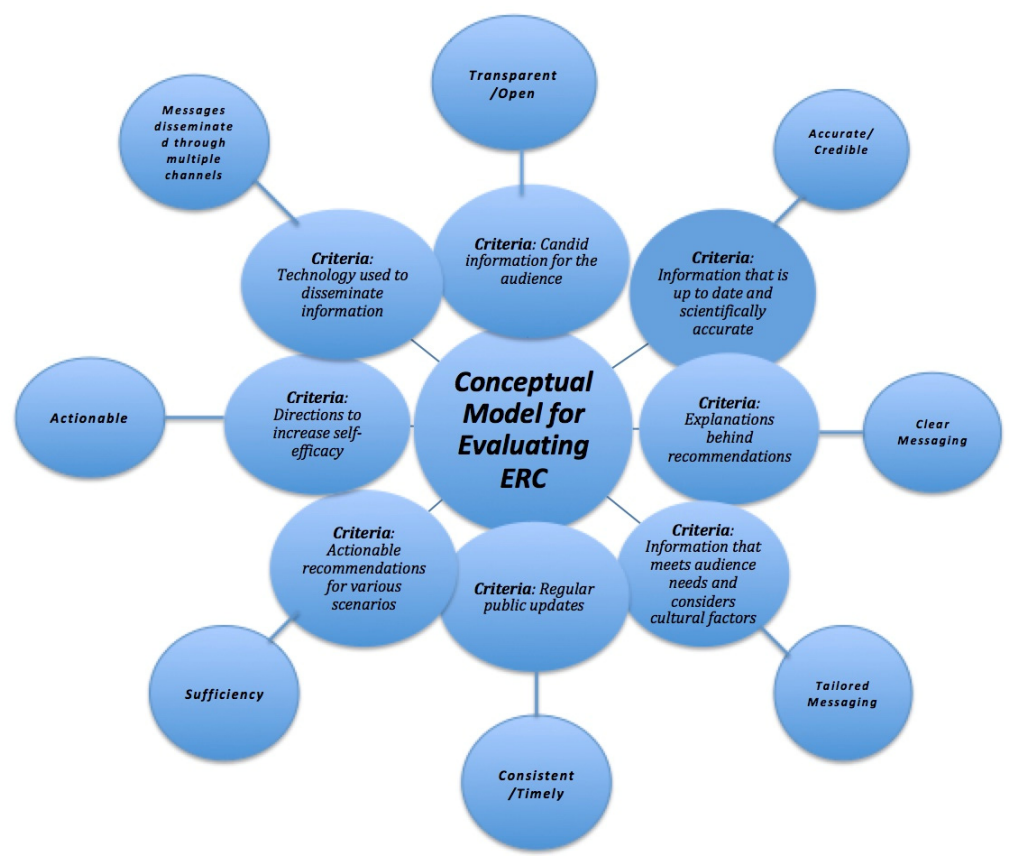

Figure 1: EERC model. (Source: Adapted from Seeger et al. [40].)

key audiences in an immediate and accessible way [40]. Information regarding the number of cases from the community as well as components that are still evolving in relation to the pandemic would be categorized under "transparent/open". The Timely and Consistent criterion ensures that messages are consistent to maintain the public's trust and decrease scepticism. The conceptual model uses consistency to portray the importance of information being aligned with other sources. While information does not have to be a replica from one source to another, providing coherent context maximizes the public's decision to take protective actions [40]. Another aspect of timeliness and consistency in risk communication is updating of information on a regular basis. In collecting information from websites of selected IHEs, information regarding a record of regular updates as well as the date from the latest updates were examined. The Actionable criterion consists of translating information into recommendations to populations that can lessen the risks and mitigate the threat. Actionable messaging can be as simple as referring an individual to a medical professional, a credible source, and offering protective measures or practices that can be used to mitigate the threat. The Tailored Messaging component involves sharing information that meets the needs of the audience and considers cultural factors. Tailored messaging can increase the perceptions of an audience's ability to utilize actionable recommendations in order to decrease risks. Information from selected IHEs that demonstrated the sharing of information specifically for the college community was grouped under "tailored messaging". The Sufficient dimension referred to the amount of information an individual needs to address a given risk; it is a precise guide that includes information and actionable recommendations that the audience can use to decide how to act. In gathering information from websites of IHEs, information that exhibited characteristics of being robust (e.g., steps and actions to take in various scenarios during COVID-19) was recorded Sufficient category. The Clear criterion 
referred to an individual's ability to process information; for example, using plain language to explain recommendations and activities or explanation of terms and scientific jargon were evaluated in this category. Finally, the Dissemination of COVID-19-related Information via Multiple Channels as well as through technological tools used to collect community data, was added to reflect elements of a disaster resilient university (DRU). Notably, during COVID-19 virtual communications and tools have been vital in raising awareness while maintaining functions, which has also been essential for IHEs. Taken together, those eight criteria provided framework for our subsequent MMCA of selected IHEs' websites. Our research sought to answer the overarching question whether and to what degree selected IHEs in Texas exhibited characteristics of a DRU during the COVID-19 pandemic.

\section{FINDINGS}

Table 2 represents patterns of findings along the 7 original criteria of the EERC while Figs 2 and 3 represent technological tools used to (a) monitor symptoms and (b) manage COVID19 , respectively. Our findings indicate that under Open/Transparent category, operations were generally labeled under "levels", "phases", "codes", "plans", "color codes", and "approaches", and consisted of sharing information related to campus guidelines and approaches being implemented during COVID-19 for Spring 2021. Notably, less than half (i.e., $46 \%$ ) of IHEs examined provided information on campus operations to users. However, majority of IHEs provided users with information regarding the plans the campus was utilizing, sharing information regarding individuals permitted back on campus, learning styles, safety recommendations, and more. Transparency on the dissemination of COVID-19 cases from the community were also recorded and categorized under this section. Accordingly, $88 \%$ of the institutions of IHEs in the sample provided the number of COVID19 community cases. Those were reported based on (a) active totals; (b) total of students; staff, and faculty cases; (c) recovered cases; and (d) cases of isolation/quarantine. IHEs that were a health program or hospital themselves, were difficult to categorize because their cases included the numbers of cases from the county, city, and or hospital. Nonetheless, the majority of IHEs did provide the number of COVID-19 cases. Findings grouped under the Accurate/Credible criterion and based on the use of credible sources in sharing COVID-19 information revealed that every IHE provided the sources used in developing COVID-19 messaging as well as recommended guidelines based on credible sources. The sources named from IHEs were as follows: Centers for Disease Control and Prevention (CDC), World Health Organization (WHO), Texas Department of Health and Human Services, US Department of State, and local, state, and federal authorities. The findings further indicate that $95 \%$ IHE used the CDC as a resource, $48 \%$ IHE used the Texas Department of Health Services (TDHS) as a resource, $25 \%$ IHE used the WHO as a resource, and 32\% IHE used other credible resources. The findings indicate that many IHEs used multiple credible sources in sharing COVID-19 information and raising awareness. Analysis of website content that provided the basis for recommendations as well as clarification of meanings behind terms and recommendations and included in the Clear category revealed that more than half of IHEs (62\%) provided general COVID-19 information exploration on their websites. COVID-19 messaging included information on the virus that causes the disease, ways of transmission, symptoms, and in rare cases, the developing variants. Slightly less than half of IHEs however (48\%) supplied definitions for terms such as isolation, quarantine, or close contact, etc. Findings related to Tailored Messaging revealed that cultural factors were rarely included in their risk communications. Notably, a minimal number of IHEs $(6 \%)$ provided options for immediate COVID-19 information translation. Much of the information collected and 
Table 2: Patterns of findings based on EERC criteria.

\begin{tabular}{|c|c|c|c|c|c|c|}
\hline Open/Transparent & Accurate/Credible & $\begin{array}{l}\text { Clear } \\
\text { Messaging }\end{array}$ & $\begin{array}{l}\text { Tailored } \\
\text { Messaging }\end{array}$ & Consistent/Timely & Sufficiency & Actionable \\
\hline $\begin{array}{r}\text { About } 43 \% \text { of IHE } \\
\text { provided information } \\
\text { on campus operations } \\
55 \% \text { of IHE did not } \\
\text { provide campus } \\
\text { operations } \\
\\
\text { About } 82 \% \text { of IHE } \\
\text { provided COVID-19 } \\
\text { community cases } \\
\text { updates } \\
18 \% \text { of IHE did not } \\
\text { provide community } \\
\text { case updates }\end{array}$ & $\begin{array}{l}\text { About } 89 \% \text { of IHE } \\
\text { used the CDC as a } \\
\text { credible resource } \\
11 \% \text { of IHE did not } \\
\text { use the CDC as a } \\
\text { source } \\
\text { About } 45 \% \text { of IHE } \\
\text { used the Texas } \\
\text { Health and Human } \\
\text { Services as a } \\
\text { credible resource } \\
55 \% \text { of IHE did not } \\
\text { use the Texas Health } \\
\text { and Human Services } \\
\text { About } 23 \% \text { of IHE } \\
\text { used the WHO as a } \\
\text { credible resource } \\
77 \% \text { of IHE did not } \\
\text { use the WHO as a } \\
\text { credible source } \\
\text { 30\% provided other } \\
\text { credible resources } \\
\text { not listed above }\end{array}$ & $\begin{array}{l}\text { About } 58 \% \text { of } \\
\text { IHE provided } \\
\text { an overview } \\
\text { of COVID-19 } \\
42 \% \text { of IHE } \\
\text { did not provide } \\
\text { an overview of } \\
\text { COVID-19 } \\
\\
\text { About } 45 \% \text { of } \\
\text { IHE defined } \\
\text { terms } \\
55 \% \text { of IHE } \\
\text { did not define } \\
\text { terms }\end{array}$ & 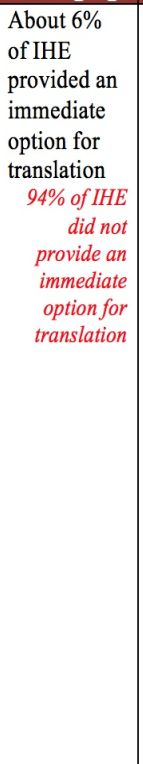 & $\begin{array}{l}\text { About } 81 \% \text { of IHE } \\
\text { provided recent } \\
\text { updates within the } \\
\text { past two months } \\
\text { About } 19 \% \text { provided } \\
\text { updates before the } \\
\text { last two months }\end{array}$ & $\begin{array}{l}100 \% \text { of } \\
\text { schools } \\
\text { provided } \\
\text { reporting } \\
\text { guidelines }\end{array}$ & $\begin{array}{l}100 \% \text { of IHE } \\
\text { provided } \\
\text { safety } \\
\text { recommendati } \\
\text { ons and } \\
\text { protocols }\end{array}$ \\
\hline
\end{tabular}

inserted in this section referred community members to other information provided on websites of campus operations, buildings opened and closed, information on signage on campus, COVID-19 testing on campus and guidelines, process of case reporting, guidelines for positive, exposed, and symptomatic cases, and return to work guidelines.

Markedly, under both Clear and Tailored Messages categories, the EERC suggests components have a duplicate impact to outcomes. When searching for data that aligned with the "clear" less than $60 \%$ of IHE defined terms, reviewed general COVID-19 information, and identified at risk groups. Although, IHE provided information on COVID-19, the information listed above altogether was not posted on each website. Thus, while some websites provided the definitions for "close contact", "quarantine", "isolation", and an overview of COVID-19, others provided other useful information. Alarmingly, less than half were found to have provided information regarding at risk groups. Findings related to Timeliness and Consistency of updates pointed to the majority of the IHEs disseminating information to the campus regarding COVID-19 since the beginning of 2020; by the time of our analysis in March 2021, 81\% of IHEs provided updates within the two previous months, yet only $19 \%$ of IHEs published their last updates in the months before March 2021. With respect to Sufficiency, $100 \%$ of IHEs provided reporting guidelines for their community for positive, exposed, or symptomatic cases and all IHEs displayed detailed information for their campuses describing enabling actions to be taken when it comes to reporting, safety recommendations, and other operations on campus during COVID-19. Finally, results related to Actionable messaging (safety recommendations provided in order to lessen the impact or risk of a hazard, recommendations during COVID-19) revealed 100\% of IHEs displayed safety recommendations and protocols for the community and recommendations such as 
wearing a face covering, practicing good hand hygiene, following the guidelines for hand washing, social distancing, daily self-monitoring and screening, practicing respiratory etiquette, and staying home if sick.

As digital health is tied to risk communication, Fig. 2 provides an overview of the ways that technology and digital health have been used in managing risks by selected IHEs in Texas. More than half $(68 \%)$ of IHEs recommended self-monitoring and self-screening; however, the use of apps, online symptom checklists, health surveys, self-screening questions, and self-monitoring guides were provided and detailed only on $12 \%$ of websites. Only $16 \%$ of IHE leveraged technology to implement daily health screenings, and only $4 \%$ of IHE leveraged technology for daily in person health screenings.

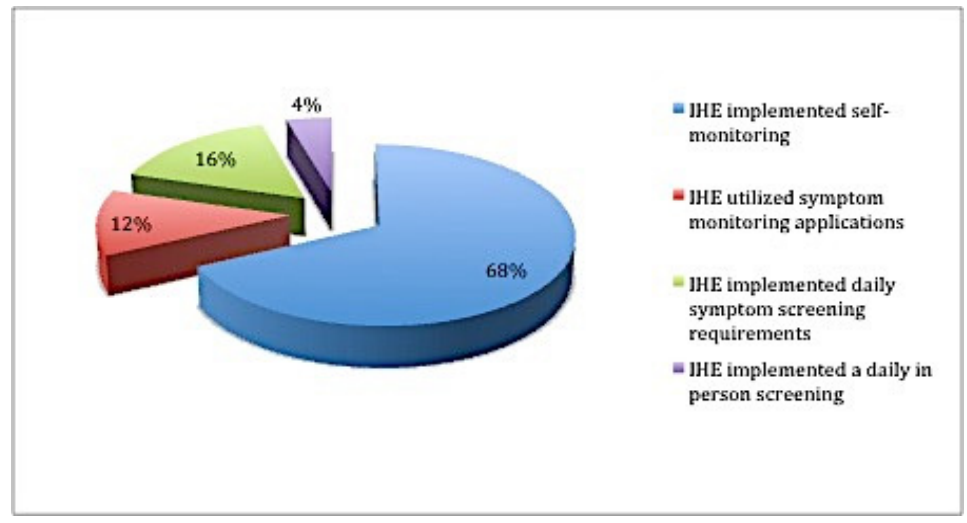

Figure 2: IHEs' use of technology to monitor COVID-19 symptoms.

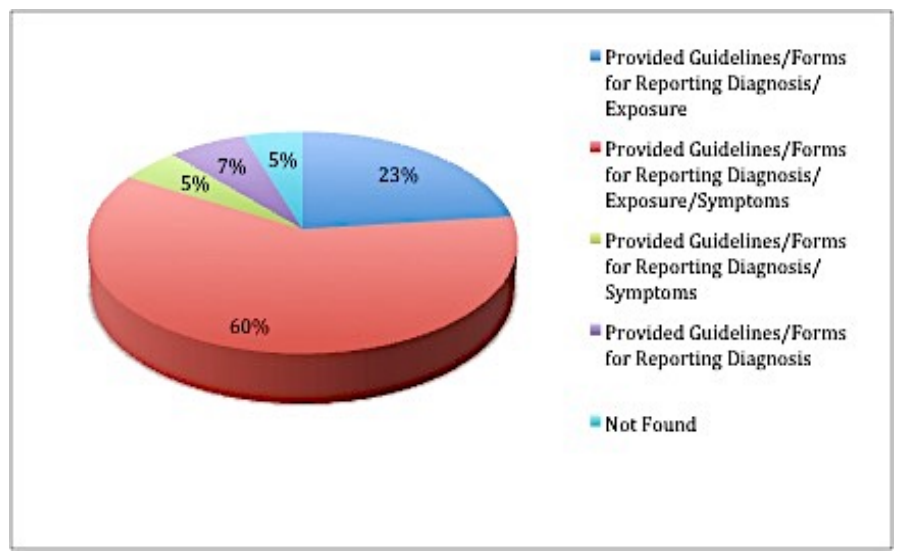

Figure 3: Technological tools to manage COVID-19.

Fig. 3 provides data collected from selected IHE used to collect COVID-19 community case information as well as enhance transparent risk communication. The findings indicate that all IHEs in our sample have developed a system to collect data on positive, exposed, or symptomatic community cases. The findings indicate that nearly a quarter $(23 \%)$ of IHE 
supplied guidelines/forms for reporting COVID-19 diagnosis and exposure, more than half $(60 \%)$ provided guidelines/forms for reporting COVID-19 diagnosis, exposure, and symptoms, merely 5\% of IHE provided guidelines/forms for reporting COVID-19 diagnosis and symptoms, and only 7\% provided guidelines for reporting COVID-19 diagnosis; 5\% were not found.

\section{DISCUSSION AND IMPLICATIONS}

The findings indicate that there are various components that IHEs targeted when communicating COVID-19 related information to their campus communities. Based on EERC criteria, IHEs biggest strengths resided in Sufficient and Actionable categories. The findings indicate that institutions disseminated robust information on their websites on safety recommendations, COVID-19 testing information, travel guidelines, reporting guidelines, face covering guidelines, social distancing guidelines, quarantine and isolation guidelines, vaccine information, campus guidelines, and returning to campus guidelines. Indeed, sufficient risk communications impact the outcome of reducing uncertainty as well as support self-efficacy [40]. To that end, risk communications from IHEs in Texas might have had a positive impact on reducing uncertainty among the campus community. In tandem, IHEs addressed both expert recommendations such as daily screening or self-monitoring, wearing a face covering, social distancing, staying home if sick, practicing good hand hygiene, respiratory etiquette, cleaning guidelines, and limiting gatherings as well as their own recommendations such as reporting positive, exposure, or symptomatic cases, returning to campus guidelines, and completing COVID-19 training. The findings also indicate that institutions of higher education adopted recommendations of establishing a report schedule [21]. This was reflected through the notification from websites of updating COVID-19 case reports daily or weekly. Actionable messaging leads to increased self-efficacy, supporting the community's belief in executing preventative actions. Actionable messaging has longterm impact on behaviour change, which is also associated with "reduced levels of mortality and morbidity..." [40, p. 199]. Clearly, both federal (CDC) and state (TDHS) - and to a lesser degree international - guidelines were sourced by the majority of IHEs; thus, IHEs can be credited with becoming a clearinghouse of accurate and credible risk communications during the pandemic which is quite important given research on college students points to $60 \%$ of this population [36] accessing its information from higher education sources. While Consistent/Timely messaging was characterized by timely and regular updates provided by $80 \%$ of IHEs during initial onset of the pandemic with earliest update marked in January 2020 , risk communication messaging waned in Spring of 2021 with only $19 \%$ of the IHEs making updates monthly; this might be troublesome due to the ongoing need for vaccination information and updates among college student population at that time. Indeed, college student COVID-19 vaccine hesitancy was reported by researchers [41] in March of 2021 to be at $47.5 \%$. Clearly, the pandemic has been moving beyond the crisis response stage, but because its nature is protracted, consistency and timeliness of ongoing risk communications remain paramount particularly among student populations that have been identified as a subgroup with high infectiousness concurrent with high vaccination hesitancy. Admittedly, IHEs in our study used technology and digital health to collect data such as positive, exposed, or symptomatic cases of COVID-19, to foster self-awareness as well as support community safety by monitoring symptoms. However, it is noteworthy that the overwhelming stress on self-monitoring by students ((nearly three fourths of IHEs) was not paralleled by availability of technological solutions to monitor symptoms (i.e., displayed only by $12 \%$ of IHEs). That divergence can be problematic from the self-efficacy standpoint. Finally, results on clarity as well as tailoring of risk communications point to IHEs needing to strengthen how they define 
terms, review general COVID-19 information, and most importantly identify at risk groups. Issues of identification of at-risk groups in pandemics by college students has been previously reported in literature whereby more than half college students incorrectly identified at risk groups and less than $25 \%$ accurately pointed out the signs and symptoms of COVID-19 [34]; our study confirms IHEs efforts in risk communications identifying at-risk groups remain ineffective with potential vulnerability in regard to knowledge of COVID-19 and precautionary data. Similarly, the element of tailored messaging was found to be a weakness of selected IHEs in our research. Only $6 \%$ of IHEs in our sample were culturally/linguistically responsive in their risk communications, yet universities exist in social contexts of communities in which they operate to include the microsystem of students' lives and their associated households. Thus, uncovered lack of cultural consideration could impact in turn the surrounding community understanding of the virus overall.

This research is not without limitations; first, not included in analysis were email communications IHEs might have used to communicate with students, faculty, and staff. Moreover, while this study gauges to what extent IHEs leveraged elected criteria of effective risk communications through design of its website platforms, it does not address students' perceptions of such. Even though technologies and digital health solution are displayed, their levels of use could not be ascertained. We propose that ongoing COVID-19 and IHE research focus on college communities' use of specific digital health tools to determine the degree and effectiveness of use and effectiveness. As Institutions of Higher Education (IHE) strive at DRU classification, exploring other channels of communication such as social media and text (SMS) in communicating risks to college students could further expand research on risk communication dissemination and consumption.

\section{ACKNOWLEDGEMENT}

The authors would like to thank Mr. ShuQi Zhang for sponsoring graduate student research.

\section{REFERENCES}

[1] World Health Organization (WHO), General information on risk communication. 2015. https://www.who.int/risk-communication/background/en/. Accessed on: 1 Jul. 2021.

[2] Bradley, D.T., McFarland, M. \& Clark, M., The effectiveness of disaster risk communication: A systematic review of intervention studies. PLoS Currents, 6, 2014. DOI: $10.1371 /$ currents.dis.349062e0db1048bb9fc3a3fa67d8a4f8.

[3] Rubin, H., OECD/IFP project on "Future Global Shocks". Organisation for Economic Co-operation and Development, 2011.

https://www.oecd.org/fr/gov/risques/Pandemics.pdf.

[4] Covello, V. \& Sandman, P.M., Risk Communication: Evolution and Revolution, John Hopkins University Press, 2004. https://www.psandman.com/articles/covello.htm.

[5] Leiss, W., Three phases in the evolution of risk communication practice. The Annals of the American Academy, 1966. DOI: 10.1177/0002716296545001009.

[6] Covello, V.T., Best Practices in Public Health Risk and Crisis Communication, Taylor and Francis Health Sciences, 2003. DOI: 10.1080/713851971.

[7] Abrams, E.M. \& Greenhawt, M., Risk Communication during COVID-19. The Journal of Allergy and Clinical Immunology, 2020. DOI: 10.1016/j.jaip.2020.04.

[8] Paulik, L., Keenan, R.E. \& Durda, J.L., The case for effective risk communication: Lessons from a global pandemic. Integrated Environmental Assessment and Management, 16(5), pp. 552-554, 2020. DOI: 1010.1002/ieam.4312. 
[9] World Health Organization, Risk communication strategy for public health emergencies in the WHO south-east Asia region: 2019-2023, 2019.

https://apps.who.int/iris/handle/10665/326853. Accessed on: 1 Jul. 2021.

[10] Glik, D.C., Risk communication for public health emergencies. Annual Review of Public Health, 28, pp. 33-54, 2007.

DOI: 10.1146/annurev.publhealth.28.021406.144123.

[11] Janoske, M., Liu, B. \& Sheppard, B., Understanding risk communication best practices: A guide for emergency managers and communicators. Report to Human Factors/Behavioral Sciences Division, Science and Technology Directorate, US Department of Homeland Security, START: College Park, MD, 2012.

[12] Holroyd, T., Oloko, O., Salmon, D., Omer, S. \& Limaye, R., Communicating recommendations in public health emergencies: The role of public health authorities. Health Security, 18(1), 2020. DOI: 10/1089/hs.2019.0073.

[13] Zhang, L., Li, H. \& Chen, K., Effective risk communication for public health emergency: Reflection on the COVID-19 (2019-nCoV) outbreak in Wuhan, China. Healthcare, 8(64), pp. 1-14, 2020. DOI: 10.3390/healthcare8010064.

[14] Paek, H. \& Hove, T., Risk Perceptions and Risk Characteristics, Communication. Online Risk Perceptions and Risk Characteristics, Oxford Research Encyclopaedia of Communication.

[15] The psychology of risk perception, Harvard Mental Health Letter, 27(12), p. 6, 2011. https://www.health.harvard.edu/newsletter_article/the-psychology-of-risk-perception. Accessed on: 1 Jul. 2021.

[16] Porat, T., Nyrup, R., Calvo, R.A., Paudyal, P. \& Ford, E., Public health and risk communication during COVID-19-enhancing psychological needs to promote sustainable behavior change., Frontiers in Public Health.

https://www.ncbi.nlm.nih.gov/pmc/articles/PMC7652763/. Accessed on: 1 Jul. 2021.

[17] Barua, Z., Barua, S., Aktar, S., Kabir, N. \& Li, M., Effects of misinformation on COVID-19 individual responses and recommendations for resilience of disastrous consequences of misinformation. Progress in Disaster Science, 8, pp. 1-9, 2020.

DOI: $10.1016 /$ j.pdisas.2020.100119.

[18] Alwashmi, M.F., The use of digital health in the detection and management of COVID19. International Journal of Environmental Research and Public Health, 17(8), 2020. DOI: $10.3390 /$ ijerph17082906.

[19] Dransch, D., Rotzoll, H. \& Poser, K., The contribution of maps to the challenges of risk communication to the public. International Journal of Digital Earth, 3(3), pp. 292-311, 2020. DOI: 10.1080/17538941003774668.

[20] World Health Organization, Communicating risk in public health emergencies. 2018. https://www.who.int/publications/i/item/9789241550208. Accessed on: 11 Jul. 2021.

[21] Hamilton, J.J. \& Hopkins, R.S., Using technologies for data collection and management, Centers for Disease Control and Prevention, 2021.

[22] Centers for Disease Control and Prevention (CDC), Considerations for institutions of higher education, 2021. https:/www.cdc.gov/coronavirus/2019-ncov/community/ colleges-universities/considerations.html. Accessed on: 1 Jul. 2021.

[23] Observations from the ongoing coronavirus (COVID-19) disease outbreak, 2020. https://www.ehtel.eu/covid-19-and-digital-health/public-health-emergencies-anddigital-health.html. Accessed on: 1 Jul. 2021.

[24] Blanchard, B., Canton, L., Cwiak, C., Gess, K., McEntire, D., Newsome, L., Selves, M., Sorchik, E., Stenson, K., Turner III, J., Waugh Jr., W. \& West, D., Principles of Emergency Management Supplement, 2007. 
[25] US Department of Homeland Security, US national infrastructure protection plan education facilities subsector, Homeland Security Digital Library, 2011.

https://www.hsdl.org/?view\&did=763303. Accessed on: 1 Jul. 2021.

[26] Denham, M.A. \& Khemka, A.K., Homeland security and emergency management in institutions of higher education (IHE): Texas case study. International Journal of Safety and Security Engineering, pp. 1-15, 2017.

[27] Kapuçu, N. \& Khosa, S., Disaster Resiliency and Culture of Preparedness for University and College Campuses, SAGE. DOI: 10.1177/0095399712471626.

[28] The New York Times, Tracking the coronavirus at U.S. colleges and universities, 2021. https://www.nytimes.com/interactive/2020/us/covid-college-cases-tracker.html. Accessed on: 1 Jul. 2021.

[29] Wrighton, M.S. \& Lawrence, S.J., Reopening colleges and universities during the COVID-19 pandemic. Annals of Internal Medicine, 2020.

[30] Budd, J., Miller, B.S., Manning, E.M., Lampos, V., Zhuang, M., Edelstein, M. \& McKendry, R.A., Digital technologies in the public-health response to COVID-19. Nature News, 2020. https://www.nature.com/articles/s41591-020-1011-4. Accessed on: 1 Jul. 2021.

[31] Kapucu, N. \& Khosa, S., Disaster Resiliency and Culture of Preparedness for University and College Campuses, SAGE, 2013. DOI: 10.1177/0095399712471626.

[32] American College Health Association, Considerations for reopening institutions of higher education for the spring semester 2021. https://www.acha.org/documents/ resources/guidelines/ACHA_Considerations_for_Reopening_IHEs_for_Spring_2021 .pdf.

[33] Mas, F.S., Jacobson, H.E. \& Olivarez, A., Communicating H1N1 risk to college students: A regional cross-sectional survey study. Journal of Homeland Security and Emergency Management, 2012. https://www.researchgate.net/publication/ 271382910_Communicating_H1N1_Risk_to_College_Students_A_Regional_CrossSectional_Survey_Study.

[34] Chesser, A., Drassen, A. \& Woods, N.K., Assessment of COVID-19 knowledge among university students: Implications for future risk communication strategies. Health Education and Behavior. DOI: 10.1177/1090198120931420.

[35] Ding, Y., Du, X., Li, Q., Zhang, M., Zhang, Q., Tan, X. \& Liu, Q., Risk perception of coronavirus disease 2019 (COVID-19) and its related factors among college students in China during quarantine. PLOS One, 2020. https://journals.plos.org/plosone/ article?id=10.1371\%2Fjournal.pone.0237626. Accessed on: 1 Jul. 2021.

[36] Callahan, M., Faced with a daily barrage of news, college students find it hard to tell what's real and what's "fake news", 2018. https://news.northeastern.edu/2018/10/16/ faced-with-a-daily-barrage-of-news-college-students-find-it-hard-to-tell-whats-realand-whats-fake-news/. Accessed on: 1 Jul. 2021.

[37] Stanley, M., Communicating risk to student populations. DRU Workshop 2011, Presentations: Disaster Resistant University Workshop: Building Partnerships in Mitigation. Paper 32. https://scholarworks.uno.edu/dru2011/32. Accessed on: 1 Jul. 2021.

[38] Serafini, F. \& Reid, S.F., Multimodal content analysis: Expanding analytical approaches to content analysis. Visual Communications, pp. 1-27, 2019.

[39] Onwuegbuzie, A.J. \& Denham, M.A., Qualitative Data Analysis Techniques, Oxford University Press: New York, 2014. 
[40] Seeger, M.W., Pechta, L.E., Price, S.M., Lubell, K.M., Rose, D.A., Sapru, S. \& Smith, B.J., A conceptual model for evaluating emergency risk communication in public health. Health Security, 2018. DOI: 10.1089/hs.2018.0020.

[41] Sharma, M., Davis, R.E. \& Wilkerson, A.H., COVID-19 vaccine acceptance among college students: A theory-based analysis. International Journal of Environmental Research and Public Health, 18(9), p. 4617, 2021. DOI: 10.3390/ijerph18094617. 